Cómo citar este trabajo: Arboleda Goldaracena, Juan Carlos (2020). Las cofradías de la Baja Andalucía y su relación con el vino (ss. XIV-XVI). Bajo Guadalquivir y Mundos Atlánticos, 02. 75-85. https://doi.org/10.46661/bajoguadalquivirmundosatl.5318

\title{
Las cofradías de la Baja Andalucía y su relación con el vino (ss. XIV-XVI)
}

\section{Confraternities in Western Andalusia and their connection with wine (14th-16th centuries)}

\author{
Juan Carlos Arboleda Goldaracena \\ Universidad Pablo de Olavide \\ jcarbgol@upo.es \\ ORCID: https://orcid.org/0000-0002-5798-5010
}

\section{Resumen}

En el presente trabajo estudiamos la vinculación de las hermandades y cofradías de la Baja Andalucía con el mundo del vino en el marco comprendido entre finales de la Edad Media y el primer siglo de la Edad Moderna. Lo hacemos utilizando para ello documentación de diverso tipo, entre la que destacan los estatutos de las propias corporaciones y los documentos procedentes de los registros notariales de los principales núcleos urbanos del Reino de Sevilla.

Palabras clave: cofradías, Andalucía, vino.

Abstract

In this work we aim to study the connection between confraternities and wine in Western Andalusia at the end of the Middle Ages and during the Early Modern Period. We have used different kinds of documents, especially confraternities' rules and notarial documentation from the most important cities around the Kingdom of Seville.

Keywords: Confraternities, Andalusia, wine. 


\section{Introducción}

Las hermandades y cofradías han constituido, desde los años finales de la Edad Media, uno de los ejes vertebradores de la sociedad y la religiosidad andaluzas, con una incidencia importantísima aún en la actualidad. Estas instituciones puramente laicales han actuado durante todos estos siglos no solamente como un elemento característico de la práctica de la religión cristiana en estas latitudes, sino como un factor importantísimo de aglutinación social. De esta manera, las cofradías han participado y participan de todos los ámbitos de la vida de la sociedad en los distintos marcos temporales y geográficos donde se ubican. El mundo del vino ${ }^{1}$, que en muchos lugares ha supuesto durante siglos un sector importante dentro de las economías locales y regionales, no podía quedar al margen de esta realidad. En este trabajo pretendemos aproximarnos a la relación de las cofradías de la Baja Andalucía con el sector de la producción vinícola durante los siglos finales de la Edad Media -momento fundamental en

1 BORRERO FERNÁNDEZ, Mercedes. "La viña en Andalucía durante la Baja Edad Media”. En IGLESIAS RODRÍGUEZ, Juan José (Coord.). Historia y cultura del vino en Andalucía. Sevilla: Universidad de Sevilla, 1995, pp. 53-62; MARTín RODRíGUEZ, José Luis. "Comer y beber en la Edad Media. El vino: alimento, medicina, alegría”. Historia 16, 1994, no 223, pp. 102-112.

2 Utilizamos ambos términos indistintamente, puesto que en la práctica aluden a las mismas realidades. Para un profundo conocimiento sobre ellas es necesario acudir a las obras del profesor José Sánchez Herrero. Entre las muchas obras que ha escrito, solo o en colaboración con otros autores, destacamos algunas: SÁNCHEZ HERRERO, José. "Las cofradías sevillanas. Los comienzos". En SÁNCHEZ HERRERO, José et al. (Eds.). Las cofradías de Sevilla: historia, antropología, arte. Sevilla: Universidad de Sevilla, 1985, pp. 9-34; "Las cofradías de Semana Santa de Sevilla durante la modernidad. Siglos XV a XVII". En SÁNCHEZ MANTERO, Rafael et al. (Eds.). Las cofradías de Sevilla en la modernidad. Sevilla: Universidad de Sevilla, 1988, pp. 27-88; "El origen de las cofradías penitenciales". En VV.AA. (Eds.). la conformación del movimiento cofrade- y la primera centuria de la modernidad.

Definimos las hermandades y cofradías $^{2}$ como asociaciones preferentemente de laicos, hombres y mujeres, que se unen para diversos fines (principalmente, adorar a Dios y venerar a la Virgen y a los santos; hacer penitencia; y ejercer la caridad), siempre teniendo como marco el de una vida cristiana según las enseñanzas evangélicas ${ }^{3}$. Nacen en la Plena Edad Media y van configurándose en torno a diversas tipologías, entre las cuales destacarán por su importancia las cofradías de Semana Santa o Pasión, que no surgirán sino hasta finales del siglo XV $y$, sobre todo, durante las primeras décadas del XVI. Nosotros, en principio, no haremos distinción en cuanto a la diversidad de cofradías, puesto que todas ellas estaban imbricadas de la misma manera dentro de la sociedad que las acogía. Las cofradías andaluzas del Antiguo Régimen han recibido una especial atención investigadora en los últimos años ${ }^{4}$, destacando dos vertientes complementarias entre sí en función de la documentación utilizada para el acercamiento a esta realidad:

Sevilla Penitente. Sevilla: Gever, 1995, vol. I, pp. 1355; "El origen de las cofradías de Semana Santa o de Pasión en la Península Ibérica". Temas Medievales, 1996, no 6, pp. 31-79; La Semana Santa de Sevilla. Madrid: Sílex, 2003; SÁNCHEZ HERRERO, José y PÉREZ GONZÁLEZ, Silvia María. "La Cofradía de la Preciosa Sangre de Cristo de Sevilla. La importancia de la devoción a la Preciosa Sangre de Cristo en el desarrollo de la devoción y la imaginería de la Semana Santa". Aragón en la Edad Media. Homenaje a la profesora Carmen Orcástegui Gros, 1999, no 14-15, pp. 1429-1452.

3 SÁNCHEZ HERRERO, José. La Semana Santa de Sevilla, ob.cit, pp. 21-22.

4 Un estudio recopilatorio relativamente reciente sobre la producción historiográfica hasta la fecha en el ámbito castellano es el de MARTíN-VIVEROS TAJUELO, Antonio. "Las cofradías castellanas en la Edad Media. Pasado, presente y futuro de la producción historiográfica". Espacio, Tiempo y Forma. Serie III. Ha Medieval, 2012, no 25, pp. 285308. 
la documentación procedente de las propias cofradías, especialmente sus reglas 0 estatutos $^{5}$; y los registros notariales ${ }^{6}$. En este trabajo haremos uso sobre todo del primer grupo de fuentes, completando la información obtenida con datos de otros estudios que han utilizado la documentación notarial, todo ello para intentar conformar un panorama lo más amplio posible en torno a esta relación entre las cofradías y el vino.

\section{El vino y su importancia litúrgica: la devoción a la sangre de cristo y su presencia en la eucaristía}

Sabido es que el vino juega un papel fundamental en la liturgia cristiana, sobre todo por su uso en la Eucaristía, durante la

5 SÁNCHEZ HERRERO, José (Dir.) y PÉREZ GONZÁLEZ, Silvia María (Coord.). CXIX Reglas de Hermandades y Cofradías Andaluzas. Siglos XIV, XV y XVI. Huelva: Universidad de Huelva, 2002; PÉREZ GONZÁLEZ, Silvia María (Dir.) y ARBOLEDA GOLDARACENA, Juan Carlos (Coord.). CXXII Reglas de Hermandades y Cofradías Andaluzas. Huelva: Universidad de Huelva, 2017; ARBOLEDA GOLDARACENA, Juan Carlos. "La caridad en la historia del cristianismo: algunas manifestaciones en la Andalucía bajomedieval". Medievalista, 2013, no 14. Disponible En http://www2.fcsh.unl.pt/iem/medievalista/MEDIE VALISTA14/goldaracena1403.html [consulta: 16/07/2019]; ARBOLEDA GOLDARACENA, Juan Carlos. "La práctica de la doctrina cristiana en las cofradías de Sevilla durante la Baja Edad Media y los comienzos de la modernidad". En RODA PEÑA, José (Dir.). XVI Simposio sobre Hermandades de Sevilla y su provincia. Sevilla: Fundación Cruzcampo, 2015, pp. 15-40; ARBOLEDA GOLDARACENA, Juan Carlos. "La religiosidad de las cofradías en la Sevilla de los siglos XIV al XVI: sacramentos, ciclo litúrgico y prácticas devocionales". Historia. Instituciones. Documentos, 2016, no 43, pp. 11-30; ARBOLEDA GOLDARACENA, Juan Carlos. "Creencias y devociones en las cofradías sevillanas de finales de la Edad Media y comienzos de la modernidad". Revista de Humanidades, 2016, no 29, pp. 9-36. Para las menciones a los distintos documentos usados en este trabajo, indicaremos a pie de página el nombre cual los cristianos creen que la consagración lo transforma en la verdadera Sangre de Cristo. Por tanto, el vino está ligado indefectiblemente a esta devoción cristífera, que puede expresarse en dos vertientes: como devoción pasionaria, representando la Sangre derramada por Jesucristo durante su Pasión; y como devoción eucarística en la que Cristo se manifiesta verdaderamente a través del vino convertido en su Sangre. Estas dos devociones están, desde sus inicios, muy presentes en las cofradías.

\subsection{La Sangre de Cristo como devoción pasionaria}

Los momentos iniciales del movimiento cofrade, allá por las postrimerías de la Edad Media, están íntimamente ligados a una de las devociones cristíferas fundamentales de este período: la veneración de la Sangre de Cristo ${ }^{7}$,

de la cofradía y el volumen recopilatorio en el que se recoge el documento.

6 PÉREZ GONZÁLEZ, Silvia Mạ. Los laicos en la Sevilla bajomedieval: sus devociones y cofradías. Huelva: Universidad de Huelva, 2005; PÉREZ GONZÁLEZ, Silvia María. "Nuevas aportaciones al estudio de las cofradías y hermandades en la Castilla bajomedieval: el ejemplo de Jerez de la Frontera". Hispania Sacra, 2016, vol. 68, n. 138, pp. 503-520; BAREA RODRígUEZ, Manuel Antonio y PÉREZ GONZÁLEZ, Silvia María. "Las cofradías jerezanas y su implicación social a través de las escribanías públicas de la ciudad (1391-1504)". Estudios sobre patrimonio, cultura y ciencias medievales, 2018, n응 20, pp. 23-46; ARBOLEDA GOLDARACENA, Juan Carlos. "Las cofradías de Alcalá de Guadaíra a fines de la Edad Media". Revista de Humanidades, 2019, no 36, pp. 11-31.

7 Para todo lo referente a esta devoción, seguirnos la línea argumental planteada en los siguientes trabajos del profesor Sánchez Herrero: SÁNCHEZ HERRERO, José. "Piedad y artes plásticas. La devoción a la Preciosa Sangre de Cristo durante los siglos XIII a los primeros años del XVI y su influencia en las manifestaciones artísticas". En Actas do Colóquio Internacional: Piedade popular. Sociabilidades-Representaçoes-Espiritualidades. 
que se fundamenta en algunos pasajes del Nuevo Testamento ${ }^{8}$. La exégesis bíblica incidió en la consideración de la Sangre de Cristo como el precio de la salvación, influyendo de manera notable en la conformación de esta devoción, que se materializó en numerosos elementos: menciones en los testamentos, en los que el testador se encomienda a la "Preciosísima" Sangre de Cristo; la representación artística de la prensa mística, en la que se comparan las uvas que han de ser prensadas para obtener el vino y los dolores padecidos por Cristo por la redención de la humanidad; la visión de Cristo como fuente de la vida, que radica en su Sangre; o la representación de Cristo con abundantes llagas. Numerosos autores como santa Brígida de Suecia, Juan de Olivi o santa Ángela de Foligno contribuyeron a la expansión de esta devoción pasionaria a fines de la Edad Media.

Esta devoción, junto con la de la Vera $\mathrm{Cruz}^{9}$, será uno de los pilares conformadores del surgimiento de las cofradías penitenciales a principios del siglo XVI. A estas dos devociones, que van indefectiblemente de la mano, se les unirá el movimiento de los flagelantes, introducido en la Península por san Vicente Ferrer con sus predicaciones a finales del siglo XIV o principios del $X V^{10}$, conformando así los tres elementos clave que

Terramar: Lisboa, 1999, pp. 411-432; SÁNCHEZ HERRERO, José y PÉREZ GONZÁLEZ, Silvia María. “La Cofradía de la Preciosa Sangre... ob. cit.; SÁNCHEZ HERRERO, José. La Semana Santa de Sevilla, ob.cit., pp. 62-66.

8 Mt 26, 28; 1 Cor 11, 25; Ef 1, 4; Col 1, 15; Heb 9, 14.

9 SÁNCHEZ HERRERO, José. La Semana Santa de Sevilla, ob.cit, pp. 55-56.

10 SÁNCHEZ HERRERO, José. "El origen de las cofradías penitenciales", ob.cit., p. 42.

11 SÁNCHEZ HERRERO, José y PÉREZ GONZÁLEZ, Silvia María. "La Cofradía de la Preciosa Sangre... ob. cit.

12 En Sevilla hubo varias desde los siglos XV y XVI. SÁNCHEZ HERRERO, José y PÉREZ GONZÁLEZ, Silvia María. "La Cofradía de la Preciosa Sangre... ob. cit. están presentes en el origen de este tipo de cofradías ${ }^{11}$.

La devoción a la Sangre de Cristo está presente por tanto en las cofradías, sobre todo en las penitenciales, ya desde su surgimiento. Y lo está tanto en las que se erigían bajo esta advocación ${ }^{12}$ como en las que lo hacían bajo otras denominaciones pero veneraban igualmente esta importante vertiente de la devoción cristífera. Las menciones en las reglas son abundantísimas. Recogeremos aquí algunos ejemplos.

Algunas cofradías se erigen para alabar a Dios por el beneficio de la redención a través de la Sangre de Jesús:

\begin{abstract}
"A honrra de la Preciosa Sangre de Nuestro Señor Jesuchristo, nos los hermanos y cofrades deseando según nuestra flaqueza y poca posibilidad y pequeñas fuerzas mostrar en algo el deseo que tenemos de servir a Dios Nuestro Señor por tan supremo bien y soberano beneficio que nos a hecho y haze en elegirnos para guarda y proteción particular de su verdadera Sangre, en la qual quiso por su muy amado Hijo le ofrecese su vida". ${ }^{13}$
\end{abstract}

En otras se resalta la fundamentación de esta devoción en su poder de mediación e intercesión:

\footnotetext{
"A honrra y seruicio de su Preçiosísima Sangre, a quien nos tenemos por abogada nuestra en todos nuestros hechos". ${ }^{14}$
}

La regla de la Hermandad del Santo Crucifijo y Sangre de Jesucristo, erigida en Écija a mediados del siglo $\mathrm{XVI}$, recoge una bella oración en la que, al inicio de cada una de las

13 Hermandad y Cofradía de las Angustias de Nuestra Señora la Virgen Santa María (Sevilla, 1541), introducción. En SÁNCHEZ HERRERO, José (Dir.) y PÉREZ GONZÁlEZ, Silvia María (Coord.). CXIX Reglas... ob.cit., regla no 7. Un texto muy similar se reproduce en la introducción de la regla de la Hermandad y Cofradía de la Santísima Trinidad (Sevilla, 1544), presente en el mismo recopilatorio (regla no 9).

14 Hermandad y Cofradía de la Preciosa Sangre (Sevilla, 1581), introducción. En SÁNCHEZ HERRERO, José (Dir.) y PÉREZ GONZÁLEZ, Silvia María (Coord.). CXIX Reglas... ob.cit., regla no 25. 
reuniones de la hermandad, los cofrades pedían a Dios, por los beneficios del derramamiento de su Sangre, que protegiera a la corporación y sus hermanos. El texto reza lo siguiente:

\begin{abstract}
"Sobre todos los señores, Señor Dios Todopoderoso, en cuya voluntad son puestas todas las cosas, rogámoste que por el derramamiento de tu preciosa Sangre, la qual siete vezes por nos derramaste, en cuio servicio y advocación nos ayuntamos, que mires en nos Tú muy piadoso Padre que esta nuestra Hermandad feziste ayuntar en este mundo para dar gloria a tu sancto Nombre, da Señor tu sancta ayuda a nos, tus siervos, que no vengan a nuestras ánimas ni a esta sancta Hermandad hescándalos ni los ayamos de padecer ni otros los ayan de sentir por nuestra causa. Y suplicámoste, Señor, que no consientas que esta nuestra Hermandad sea en abatimiento, mas acreçiéntala e consérvala en tu sancto servici<o> por el tu sancto nombre. $Y$ hincha nuestros coraçones de fee viva e de esperança e charidad e justicia, prudençia e fortaleza, temperança e castidad, obediençia, pu<r>eza, paciencia, humildad, ynoçençia, limpieza e faz a nuestros regidores, guiadores e perlado bivir e fazer tu voluntad a salud e salvación suya y nuestra. Haz, Señor, que te merezcamos aver por perlado e pastor. Sea hecha tu voluntad en todos nostros porque, aviendo piedad de nos, merezcamos venir a la gloria del tu sancto Reyno por Jesuchristo Nuestro Señor". ${ }^{15}$
\end{abstract}

Los cofrades del Santísimo Crucifijo de Marchena debían rezar a diario una serie de oraciones en recuerdo de la Sangre de Cristo:

\footnotetext{
"Y rezen cada día de esta vida siete Aue Marías y siete Pater Noster a honor y reuerencia de la Sangre de Nuestro Señor Jesuchristo, que siete vezes por nos derramó y de las siete palabras que Jesús
}

15 Hermandad y Cofradía del Santísimo Crucifijo y Sangre de Nuestro Señor Jesucristo (Écija, 1553, 1571), capítulo 3. En SÁNCHEZ HERRERO, José (Dir.) y PÉREZ GONZÁLEZ, Silvia María (Coord.). CXIX Reglas... ob.cit., regla $\mathrm{n}$ - 55. Una oración similar aparece en la introducción de la regla de la Hermandad y Cofradía del Santo Crucifijo (Jerez de la Frontera, 1573). En PÉREZ GONZÁLEZ, Silvia María (Dir.) y ARBOLEDA GOLDARACENA, Juan Carlos (Coord.). CXXII Reglas... ob.cit., regla no 82.

16 Hermandad y Cofradía del Santísimo Crucifijo (Marchena, 1556), capítulo 4. En SÁNCHEZ HERRERO, José (Dir.) y PÉREZ GONZÁLEZ, Silvia María (Coord.). CXIX Reglas... ob.cit., regla no 72.

17 ARBOLEDA GOLDARACENA, Juan Carlos. "La religiosidad de las cofradías en la Sevilla de los siglos XIV al XVI... ob.cit.

18 Hermandad y Cofradía de Nuestra Señora de la Esperanza (Sevilla, 1595), capítulo 10. En SÁNCHEZ crucificado dijo y de las siete angustias de la gloriosa Virgen María". ${ }^{16}$

\subsection{La Sangre de Cristo como devoción eucarística}

La misa constituía el acto de culto principal en las fiestas de las cofradías, pero no era el único momento en que los integrantes de las corporaciones se reunían para celebrar la Eucaristía: a veces se celebraban también misas del Espíritu Santo al comienzo de las reuniones, para pedir su inspiración. Algunas cofradías celebraban misa diaria, otras semanalmente o con carácter mensual ${ }^{17}$.

Las reglas especifican algunas disposiciones relacionadas con este momento fundamental de culto: los cofrades habían de guardar gran atención y devoción, "considerando que tienen a Dios delante de si"18. En las misas solemnes se utilizaba incienso ${ }^{19}$ y se debía tener la cera encendida en determinados momentos: "en Vísperas a la oraçión Magnifica y responso y en misa al Euangelio y a la sacras asta alçar la Hostia húltima vez"20. También se estipula que, en caso de retraso de los cofrades, su llegada a la misa no podía ser posterior al momento de leer el Evangelio, bajo sanción económica ${ }^{21}$. Entre las diversas intenciones por las que se ofrecían las misas, aparte de la conmemoración de fiestas o en

HERRERO, José (Dir.) y PÉREZ GONZÁLEZ, Silvia María (Coord.). CXIX Reglas... ob.cit., regla no 31.

19 Hermandad y Cofradía de Nuestra Señora de la Cabeza (Sevilla, 1564), capítulo 3. En SÁNCHEZ HERRERO, José (Dir.) y PÉREZ GONZÁLEZ, Silvia María (Coord.). CXIX Reglas... ob.cit., regla no 13.

20 Hermandad y Cofradía de la Limpia y Pura Concepción de Nuestra Señora la Virgen María

del Convento de Regina (Sevilla, 1549), capítulo 14. En SÁNCHEZ HERRERO, José (Dir.) y PÉREZ GONZÁLEZ, Silvia María (Coord.). CXIX Reglas... ob.cit., regla no 10.

21 Hermandad y Cofradía de la O (Sevilla, 1566), capítulo 43. En SÁNCHEZ HERRERO, José (Dir.) y PÉREZ GONZÁLEZ, Silvia María (Coord.). CXIX Reglas... ob.cit., regla $\mathrm{n}$ ㅇ 18. 
calidad de sufragio por los difuntos ${ }^{22}$, destacamos la lucha contra las herejías ${ }^{23}$ o el apoyo espiritual a los príncipes cristianos ${ }^{24}$.

Algunas cofradías tenían un clérigo o capellán encargado de decir las diversas misas ${ }^{25}$ y en otras se realizaban colectas entre los cofrades para la celebración de estos cultos ${ }^{26}$. Si los cofrades no acudían a misa los domingos y fiestas en la cofradía, habían de hacerlo en su parroquia más cercana, como mandan las normas de la Iglesia ${ }^{27}$. Los cofrades también tenían la obligación de acudir a la primera misa de cualquier clérigo que perteneciera a la cofradía antes de ordenarse ${ }^{28}$.

\section{Otros usos del vino en la vida de las cofradías}

Al margen de su uso durante la celebración de la Eucaristía, es posible documentar también otros momentos en los que las cofradías empleaban el vino para diversos fines. Nos referiremos fundamentalmente a la procesión de penitencia o disciplina que llevaban a cabo muchas cofradías ya desde las primeras décadas del siglo XVI.

Los desfiles penitenciales de las cofradías durante la primera centuria moderna eran bastante sencillos. En ellos participaban los

22 ARBOLEDA GOLDARACENA, Juan Carlos. "Los laicos y su actitud ante la muerte en la Sevilla de la Baja Edad Media y los comienzos de la modernidad". En MIURA ANDRADES, José María (Dir.) y ARBOLEDA GOLDARACENA, Juan Carlos (Coord.). Lágrimas en la lluvia. Estudios sobre la muerte y los muertos. Sevilla: Aconcagua, 2014, pp. 291-300.

23 Hermandad y Cofradía de Jesús Nazareno y Santa Cruz de Jerusalén (Sevilla, 1564, 1567, 1578), capítulo 1. En SÁNCHEZ HERRERO, José (Dir.) y PÉREZ GONZÁLEZ, Silvia María (Coord.). CXIX Reglas... ob.cit., regla no 15 .

24 Hermandad y Cofradía de Nuestra Señora de la Esperanza (Sevilla, 1595), capítulo 4. En SÁNCHEZ HERRERO, José (Dir.) y PÉREZ GONZÁLEZ, Silvia María (Coord.). CXIX Reglas... ob.cit., regla no 31. cofrades de dos maneras distintas: los llamados cofrades de luz componían el cortejo portando velas o candelas. Por su parte, los cofrades de sangre se integraban en el mismo disciplinándose para imitar los momentos de la Pasión de Jesús, al estilo de las compañías de disciplinantes de san Vicente Ferrer a las que ya nos hemos referido. Al final del cortejo solía portarse una pequeña imagen de Jesús crucificado o de la Virgen María vestida de luto. Los cortejos recorrían las distintas feligresías de las ciudades donde se integraban las cofradías. Las reglas describen en ocasiones fielmente en qué consistían estas procesiones, como en el caso de la Cofradía de las Cinco Llagas de Jerez:

\footnotetext{
"Ordenamos y tenemos por bien por que nuestro principal intento es que nuestra Hermandad que sea de disciplina, queremos y mandamos que la proscesión del Jueves Sancto en la noche uengan todos los hermanos de sangre y de luz antes del sol puesto o poco después con sus uestimentas blancas, como dicho es en el primero capítulo, y su disciplina o lumbre y se recojan dentro deste dicho Conuento. $Y$ que la tal disciplina se encomienço después desta, todos juntos en nuestra capilla y ayuntamento dadas las nueue. $Y$ que de aquí salgamos dadas las diez para andar las estaciones, las quales mandamos que sean siete, en que la una y principal sea la Yglesia mayor de Sanct Saluador y las demás estaciones, las que en el cabildo general del dicho Domingo de Ramos se ordenare. Y que para esta tal disciplina uengan todos confessados y comulgados, pidiendo perdón a su próximo para que nuestro Señor los oyga y resciba su penitencia. $Y$ esto les encomendamos por Jesu Christo acordándose de sus bendictas cinco Llagas y bendictíssima Sangre. Y que estando ayuntados en
}

25 Hermandad y Hospital de peregrinos de Nuestra Señora del Pilar (Sevilla, 1336), capítulo 26. En SÁNCHEZ HERRERO, José (Dir.) y PÉREZ GONZÁLEZ, Silvia María (Coord.). CXIX Reglas... ob.cit., regla no 1.

26 Hermandad y Cofradía de la Santa Verónica (Sevilla, 1565), capítulo 16. En SÁNCHEZ HERRERO, José (Dir.) y PÉREZ GONZÁLEZ, Silvia María (Coord.). CXIX Reglas... ob.cit., regla $\mathrm{n}$ ㅇ 16 .

27 Hermandad de la Santa Casa de la Misericordia (Sevilla, 1476, 1518), capítulo 35. En SÁNCHEZ HERRERO, José (Dir.) y PÉREZ GONZÁLEZ, Silvia María (Coord.). CXIX Reglas... ob.cit., regla no 4.

28 Hermandad y Cofradía de la O (Sevilla, 1566), capítulo 37. En SÁNCHEZ HERRERO, José (Dir.) y PÉREZ GONZÁLEZ, Silvia María (Coord.). CXIX Reglas... ob.cit., regla $\mathrm{n} 018$. 


\begin{abstract}
la disciplina la qual hagan delante un crucifixo e los hermanos mayores tengan cuidado de les encomendar que rezen cinco Pater Nostres con cinco Aue Marías por las ánimas de purgatorio y por los que están en pecado mortal, que Dios los trayga a uerdadero conoscimiento. $Y$ que las insignias que en esta sancta procesión an de lleuar sean aquellas que en el cabildo de Ramos se concertare. Y que de tal manera se ande la procesción que quando boluamos a la Yglesia de Señor Sanct Francisco sea después delas doze de la noche, por ganar los perdones del Viernes Sancto. $Y$ ansi mismo en el dicho Conuento mandamos que los mayordomos y diputados tengan adereçado el lauatorio con aquella cantidad y uino que fuere menester para el tal lauatorio. $Y$ que el señor administrador $y$ uisitadores uisiten $y$ se hallen en este lauatorio $y$ vean sy los penitentes van bien curados sin que en ello aya falta. $Y$ esto seles encomienda por Jesu Christo nuestro Señor." 29
\end{abstract}

En este contexto aparece la utilización del vino para varios fines: a modo de colación para dar fuerzas a los disciplinantes durante ${ }^{30}$ y después ${ }^{31}$ de la procesión; $y$, sobre todo, para aprovechar sus propiedades curativas para sanar las heridas que sufrían los cofrades tras la práctica de la disciplina. Para ello se empleaba una receta consistente en vino blanco, arrayán, romero, piña, rosas y violetas $^{32}$. El procedimiento era el siguiente:

"El adereço para el cozimiento y lauatorio, que es lo
siguiente: vino blanco, arrayhán molido, romero,
piña, rosas y violetas. Y todo esto, no suelto sino en
sus saquillos de lienço, lo echen en su caldera, una
o dos, y cuezan muy bien hasta heruir. Y este
cocimiento se comiençe a hazer a las siete de la
noche el dicho Jueues Sancto, porque aya lugar de
se hazer bien hecho. Y los que fueren nombrados
para el dicho lauatorio se queden con los del

29 Cofradía de las Cinco Llagas (Jerez de la Frontera, 1561), capítulo 19. En PÉREZ GONZÁLEZ, Silvia María (Dir.) y ARBOLEDA GOLDARACENA, Juan Carlos (Coord.). CXXII Reglas... ob.cit., regla no 80.

30 Hermandad y Cofradía de Nuestra Señora de las Aguas y Santa Expiración de Jesucristo (Sevilla, 1575), capítulo 8. En SÁNCHEZ HERRERO, José (Dir.) y PÉREZ GONZÁLEZ, Silvia María (Coord.). CXIX Reglas... ob.cit., regla no 23.

31 Hermandad y Cofradía de la Santa Vera Cruz (Lora del Río, 1555), capítulo 35. En SÁNCHEZ HERRERO, José (Dir.) y PÉREZ GONZÁLEZ, Silvia María (Coord.). CXIX Reglas... ob.cit., regla no 69 .

32 En otras cofradías se empleaba también laurel. Hermandad y Cofradía de Nuestra Señora de la Soledad (Aznalcóllar, 1590), capítulo 15. En SÁNCHEZ HERRERO, José (Dir.) y PÉREZ GONZÁLEZ, cozimiento para que estando hecho, si algunos cofrades desmayados o desangrados quebraren de la prosçessión, hallen refuxio de lauatorio. Y tengan para ello tres a quatro vaçias de açofrar grandes y su poluo de arrayhán y papel de añafea y tengan cuydado de lauar y curar los penitentes con liberalidad y charidad y amor porque Dios les pague tan buena obra." ${ }^{33}$

En otras ocasiones, el vino se empleaba para repartirlo entre los cofrades cuando se celebraba alguna conmemoración ${ }^{34}$, como la fiesta de Santa María de Agosto, una de las solemnidades marianas más importantes durante el período estudiado, en la que se recuerda la Asunción de María a los cielos en cuerpo y alma ${ }^{35}$.

\section{Las cofradías como propietarias de viñas}

Las cofradías bajomedievales y de comienzos de la modernidad basaron su economía principalmente en tres tipos de bienes: las casas, las propiedades rurales y el capital artesanal, todo ello procedente en la mayoría de ocasiones de donaciones de personas que en su testamento legaban estos bienes a las corporaciones para que estas oficiaran determinados sufragios por sus almas o se encargaran de sus entierros ${ }^{36}$. Una documentación muy rica para conocer esta realidad se halla en los fondos notariales, que

Silvia María (Coord.). CXIX Reglas... ob.cit., regla no 40.

33 Hermandad y Cofradía de la Limpia y Pura Concepción de Nuestra Señora la Virgen María

del Convento de Regina (Sevilla, 1549), capítulo 19. En SÁNCHEZ HERRERO, José (Dir.) y PÉREZ GONZÁLEZ, Silvia María (Coord.). CXIX Reglas... ob.cit., regla no 10.

34 Hermandad y Cofradía de Nuestra Señora de Agosto (Espartinas, anterior a 1539), capítulo 6. En SÁNCHEZ HERRERO, José (Dir.) y PÉREZ GONZÁLEZ, Silvia María (Coord.). CXIX Reglas... ob.cit., regla no 65.

35 ARBOLEDA GOLDARACENA, Juan Carlos. "Creencias y devociones... ob.cit.

36 PÉREZ GONZÁLEZ, Silvia Mạ . Los laicos en la Sevilla bajomedieval... ob.cit., pp. 151-168. 
son los que pulsan las relaciones de las cofradías con los distintos marcos sociales en los que se ubicaban. Para el caso de la Baja Andalucía a finales de la Edad Media hay varios estudios que se han ocupado del estudio de las cofradías en sus principales núcleos urbanos utilizando para ello los protocolos notariales. Aunque son escasos, reseñaremos aquí los datos referidos a propiedades de viñas por parte de cofradías en las principales ciudades del Reino de Sevilla.

En primer lugar, la Dra. Pérez González abordó en su tesis doctoral, publicada parcialmente ${ }^{37}$, el estudio de las cofradías sevillanas entre 1441 y 1504 a partir de la documentación notarial. En el caso sevillano, las viñas suponían un $30 \%$ del total de propiedades rurales que poseían las cofradías. A veces estas viñas eran propiedad directa de las cofradías, que las arrendaban para obtener beneficios. Otras veces, las corporaciones poseían censos sobre determinados terrenos de viña y no la propiedad en sí. Entendemos por censo las rentas sobre un determinado bien que recibe una persona -la propietaria del censo- que no es necesariamente la propietaria del citado bien. La documentación normalmente no aporta muchos datos con respecto a las características o la extensión de los distintos terrenos. Tampoco lo hace sobre las condiciones de explotación.

Un estudio más reciente, también de la Dra. Pérez González, se ha ocupado de las cofradías jerezanas a fines de la Edad Media utilizando igualmente la documentación notarial ${ }^{38}$. En él se refleja también la posesión de viñas por parte de las cofradías de la ciudad, con una mayor presencia debido al entorno rural en el que se ubicaba Jerez, por

\section{Ibídem.}

38 PÉREZ GONZÁLEZ, Silvia María. "Nuevas aportaciones al estudio de las cofradías y hermandades en la Castilla bajomedieval: el ejemplo de Jerez de la Frontera", ob.cit. delante de otros tipos de propiedades como arboleda u olivar. En el caso jerezano, a diferencia del sevillano, se ha podido documentar la compra de este tipo de terrenos por parte de una cofradía como es la Hermandad de San Luis que en 1470 adquiere a un hortelano una aranzada de viña. Un catálogo de buena parte de la documentación notarial jerezana sobre cofradías, en el que aparecen varios documentos referidos a transacciones comerciales en las que las viñas son protagonistas, es el de Barea y Pérez González ${ }^{39}$.

Otros estudios sobre cofradías en diferentes núcleos de población importantes en el Reino de Sevilla, como Alcalá de Guadaíra, no han arrojado datos sobre posesión de viñas por parte de las cofradías de la ciudad ${ }^{40}$.

\section{Vinculación de los cofrades con el sector de la producción vinícola}

Los estudios mencionados en el apartado anterior no han permitido documentar entre los cofrades la presencia de viñeros o personas vinculadas al sector de la producción vinícola ni en Sevilla ni en Jerez ni en Alcalá de Guadaíra. Bien es cierto que estos trabajos se han centrado sobre todo en la documentación de finales del siglo $\mathrm{XV}$, por lo que futuras investigaciones basadas en la documentación notarial, mucho más abundante en el siglo XVI, podrían arrojar nuevos datos. No obstante, los estudios basados en la documentación notarial sí han permitido constatar que las cofradías estaban constituidas fundamentalmente por personas pertenecientes al sector secundario de la economía, es decir, artesanos, por lo que no sería frecuente documentar en ellas a

39 BAREA RODRÍGUEZ, Manuel Antonio y PÉREZ GONZÁLEZ, Silvia María. "Las cofradías jerezanas y su implicación social... ob.cit.

40 ARBoledA goldARACENA, Juan Carlos. "Las cofradías de Alcalá de Guadaíra a fines de la Edad Media", ob.cit. 
miembros del sector primario como podrían ser los viñeros.

Aun así, y aunque suponga alejarnos levemente del marco geográfico y cronológico de nuestro estudio, queremos mencionar brevemente que en otros lugares de Andalucía sí se ha documentado la existencia de cofradías integradas por personas pertenecientes al sector del cultivo de la viña. Es el caso de la ciudad de Málaga, en la que a comienzos del siglo XVII se organiza la conocida como Hermandad de los Viñeros, que sigue existiendo en la actualidad ya no como una cofradía gremial pero sí como testigo de su presencia en siglos anteriores ${ }^{41}$.

\section{Conclusiones}

Como hemos visto, la relación de las cofradías bajomedievales y modernas en la Baja Andalucía con el mundo del vino no era demasiado extensa, aunque sí lo suficientemente importante como para poder constatarla. Esta se basaba fundamentalmente en la principal manifestación devocional del cristianismo vinculada al vino: la veneración de la Sangre de Cristo, tanto en su vertiente pasionaria como en la faceta eucarística. Las cofradías andaluzas de este período llevaron a cabo una importante labor cultual en torno a estas devociones cristíferas cruciales para el cristianismo y su religiosidad. Por otro lado, y como no podía ser de otra manera, las cofradías estaban perfectamente integradas en el seno de la sociedad de la que formaban parte. Esto hacía que, como parte de sus bases económicas, fueran propietarias de terrenos rurales dedicados al cultivo de la vid. Por último, y aunque hasta la fecha no se ha documentado la presencia de cofrades

41 PONCE RAMOS, José Miguel. La Hermandad y Montepío de Viñeros en la Edad Moderna. Málaga: Diputación de Málaga, 1995; QUINTANA TORET, Francisco Javier. "La Hermandad de Viñeros de Málaga en el siglo XVII". En VV.AA (Eds.). VII Jornadas de Viticultura y Enología de Tierra de pertenecientes a este sector económico en el marco espacio-temporal en el que nos movemos, sí que podemos reseñar la existencia de una cofradía formada por viñeros en la ciudad de Málaga ya entrada la Edad Moderna. Esto era algo infrecuente debido a que las cofradías estuvieron formadas mayoritariamente por trabajadores del sector artesanal. Aun así, el estudio de la documentación notarial, sobre todo la relativa al siglo XVI, podrá seguir arrojando más datos al respecto.

\section{Bibliografía}

ARBOLEDA GOLDARACENA, Juan Carlos. "La caridad en la historia del cristianismo: algunas manifestaciones en la Andalucía bajomedieval". Medievalista, 2013, no 14. Disponible En

http://www2.fcsh.unl.pt/iem/medievalista/ MEDIEVALISTA14/goldaracena1403.html [consulta: 16/07/2019]

ARBOLEDA GOLDARACENA, Juan Carlos. "Los laicos y su actitud ante la muerte en la Sevilla de la Baja Edad Media y los comienzos de la modernidad". En MIURA ANDRADES, José María (Dir.) y ARBOLEDA GOLDARACENA, Juan Carlos (Coord.). Lágrimas en la lluvia. Estudios sobre la muerte y los muertos. Sevilla: Aconcagua, 2014, pp. 291-300.

ARBOLEDA GOLDARACENA, Juan Carlos. "La práctica de la doctrina cristiana en las cofradías de Sevilla durante la Baja Edad Media y los comienzos de la modernidad" En RODA PEÑA, José (Dir.). XVI Simposio sobre Hermandades de Sevilla y su provincia. Sevilla: Fundación Cruzcampo, 2015, pp. 15-40.

ARBOLEDA GOLDARACENA, Juan Carlos. "La religiosidad de las cofradías en la Sevilla de los 
siglos XIV al XVI: sacramentos, ciclo litúrgico y prácticas devocionales". Historia. Instituciones. Documentos, 2016, no 43, pp. 11-30.

ARBOLEDA GOLDARACENA, Juan Carlos. "Creencias y devociones en las cofradías sevillanas de finales de la Edad Media y comienzos de la modernidad". Revista de Humanidades, 2016, no 29, pp. 9-36.

ARBOLEDA GOLDARACENA, Juan Carlos. "Las cofradías de Alcalá de Guadaíra a fines de la Edad Media". Revista de Humanidades, 2019, no 36, pp. 11-31.

BAREA RODRÍGUEZ, Manuel Antonio y PÉREZ GONZÁLEZ, Silvia María. "Las cofradías jerezanas y su implicación social a través de las escribanías públicas de la ciudad (13911504)". Estudios sobre patrimonio, cultura y ciencias medievales, 2018, no 20, pp. 23-46.

BORRERO FERNÁNDEZ, Mercedes. "La viña en Andalucía durante la Baja Edad Media". En IGLESIAS RODRÍGUEZ, Juan José (Coord.). Historia y cultura del vino en Andalucía. Sevilla: Universidad de Sevilla, 1995, pp. 5362.

MARTín RODRÍGUEZ, José Luis. "Comer y beber en la Edad Media. El vino: alimento, medicina, alegría". Historia 16, 1994, no 223, pp. 102-112.

MARTÍN-VIVEROS TAJUELO, Antonio. "Las cofradías castellanas en la Edad Media. Pasado, presente y futuro de la producción historiográfica". Espacio, Tiempo y Forma. Serie III. Hª Medieval, 2012, no 25, pp. 285308.

PÉREZ GONZÁLEZ, Silvia Mạ. Los laicos en la Sevilla bajomedieval: sus devociones y cofradías. Huelva: Universidad, 2005.

PÉREZ GONZÁLEZ, Silvia María. "Nuevas aportaciones al estudio de las cofradías y hermandades en la Castilla bajomedieval: el ejemplo de Jerez de la Frontera". Hispania Sacra, 2016, vol. 68, n. 138, pp. 503-520.
PÉREZ GONZÁLEZ, Silvia María (Dir.) y ARBOLEDA GOLDARACENA, Juan Carlos (Coord.). CXXII Reglas de Hermandades y Cofradías Andaluzas. Huelva: Universidad de Huelva, 2017.

PONCE RAMOS, José Miguel. La Hermandad y Montepío de Viñeros en la Edad Moderna. Málaga: Diputación de Málaga, 1995.

PONCE RAMOS, José Miguel. "La religiosidad de los viñeros malagueños en la Edad Moderna". En Religiosidad popular en España: actas del Simposium: 1/4-IX-1997, 1997, vol. 1, pp. 145-162.

QUINTANA TORET, Francisco Javier. "La Hermandad de Viñeros de Málaga en el siglo XVII". En VV.AA (Eds.). VII Jornadas de Viticultura y Enología de Tierra de Barros. Universidad de Extremadura, 1985, trabajo 47.

SÁNCHEZ HERRERO, José. "Las cofradías sevillanas. Los comienzos". En SÁNCHEZ HERRERO, José et al. (Eds.). Las cofradías de Sevilla: historia, antropología, arte. Sevilla: Universidad de Sevilla, 1985, pp. 9-34.

SÁNCHEZ HERRERO, José. "Las cofradías de Semana Santa de Sevilla durante la modernidad. Siglos XV a XVII". En SÁNCHEZ MANTERO, Rafael et al. (Eds.). Las cofradías de Sevilla en la modernidad. Sevilla: Universidad de Sevilla, 1988, pp. 27-88.

SÁNCHEZ HERRERO, José. "El origen de las cofradías penitenciales". En VV.AA. (Eds.). Sevilla Penitente. Sevilla: Gever, 1995, vol. I, pp. 13-55.

SÁNCHEZ HERRERO, José. "El origen de las cofradías de Semana Santa o de Pasión en la Península Ibérica". Temas Medievales, 1996, no 6, pp. 31-79.

SÁNCHEZ HERRERO, José. "Piedad y artes plásticas. La devoción a la Preciosa Sangre de Cristo durante los siglos XIII a los primeros años del XVI y su influencia en las manifestaciones artísticas". En Actas do 
Colóquio Internacional: Piedade popular. Sociabilidades-Representaçoes-

Espiritualidades. Terramar: Lisboa, 1999, pp. 411-432.

SÁNCHEZ HERRERO, José. La Semana Santa de Sevilla. Madrid: Sílex, 2003.

SÁNCHEZ HERRERO, José y PÉREZ GONZÁLEZ, Silvia María. "La Cofradía de la Preciosa Sangre de Cristo de Sevilla. La importancia de la devoción a la Preciosa Sangre de Cristo en el desarrollo de la devoción y la imaginería de la Semana Santa". Aragón en la Edad Media. Homenaje a la profesora Carmen Orcástegui Gros, 1999, no 14-15, pp. 1429-1452.

SÁNCHEZ HERRERO, José (Dir.) y PÉREZ GONZÁLEZ, Silvia María (Coord.). CXIX Reglas de Hermandades y Cofradías Andaluzas. Siglos XIV, XV y XVI. Huelva: Universidad de Huelva, 2002. 